University of Windsor

Scholarship at UWindsor

\title{
Lecture Engagement and Metamotivational States: Tracking and Intervention
}

Kenneth M. Cramer

University of Windsor

Kathryn Lafreniere

University of Windsor

Follow this and additional works at: https://scholar.uwindsor.ca/psychologypub

Part of the Psychology Commons

\section{Recommended Citation}

Cramer, Kenneth M. and Lafreniere, Kathryn. (2015). Lecture Engagement and Metamotivational States: Tracking and Intervention. Journal of Motivation, Emotion, and Personality, 4, 9-14.

https://scholar.uwindsor.ca/psychologypub/44

This Article is brought to you for free and open access by the Department of Psychology at Scholarship at UWindsor. It has been accepted for inclusion in Psychology Publications by an authorized administrator of Scholarship at UWindsor. For more information, please contact scholarship@uwindsor.ca. 


\title{
Lecture Engagement and Metamotivational States: Tracking and Intervention
}

\author{
Kenneth M. Cramer, Kathryn D. Lafreniere \\ University of Windsor
}

\begin{abstract}
We studied the underlying motives governing students' active learning in the classroom. Previous investigations indicate that during a standard lecture, student ratings of engagement decrease along with serious-mindedness (telic state). In each of two studies, a questionnaire packet was distributed to participants at the start of their 75-minute social psychology class. The instructor paused the lecture every 10 minutes (from Time 1 to Time 6) to assess the extent to which students were (a) serious-minded or telic and (b) engaged in the lecture. Results from Study 1 showed that both serious-mindedness and lecture engagement together dropped over the span of the lecture. In Study 2 we reasoned that by introducing a mid-lecture student group activity, both engagement and serious-mindedness would rebound. Between Time 3 and Time 4 , students were given a group task to complete and discuss among each other. Compared to prior data (Study 1) without the activity after Time 3, engagement and serious-mindedness were significantly higher at Time 4 before falling again at Time 6 . Educational implications and future directions are discussed.
\end{abstract}

Keywords: lecture engagement, telic vs. paratelic states

Engaging students in higher education - whether at the national or classroom level - continues to be a challenge for educators. The National Survey of Student Engagement (NSSE; http://nsse.iub.edu/) collects data annually from almost 400,000 students in Canada and the United States, enrolled at over 600 4-year colleges and universities; over 4 million students have completed the survey since its inception in the year 2000. The survey reveals how those students are spending their time at their institution and delivers to stakeholders a glimpse into an institution's best practices. As an index of college quality, its purpose is to guide students, instructors, administrators, and legislators toward improving higher education. The ultimate goal is to effectively utilize resources and to organize an efficient curriculum that optimizes student outcomes (Ahlfeld, Mehta, \& Sellnow, 2005; Axelson \& Flick, 2010; Baron \& Corbin, 2012; Coates, 2005; Kahu, 2013; Krause \& Coates, 2008; Kuh, 2001, 2003). Meanwhile, inside institutions, instructors are keen to know and improve the engagement and motivational levels of students in the classroom as the lecture is

Kenneth M. Cramer, Department of Psychology, University of Windsor; Kathryn D. Lafreniere, Department of Psychology, University of Windsor.

Correspondence concerning this article should be addressed to Kenneth M. Cramer, Psychology Department, University of Windsor, 401 Sunset Ave., Windsor, ON, N9B 3P4, Canada., E-mail: kcramer@uwindsor.ca being delivered. Efforts to maximize that engagement is the focus of this paper.

Research on student engagement and motivation shows that student learning is greatly enhanced when students are actively engaged with the topic materials (Lutze-Mann \& Kumar, 2013; Mundy \& Consoli, 2013; Winstone \& Millward, 2012). However, the level of student engagement and focus are likely to decrease as the lecture progresses and fatigue and distraction increase. Factors that return students to a more serious goal-oriented and less distracted state should similarly enhance student learning and engagement. Using two studies, we evaluated both (a) whether student engagement and serious-mindedness could be tracked (and correlated) throughout an on-going lecture and (b) whether lecture engagement could be returned to originally high levels following a student group activity within the main lecture.

Research in the past decade has challenged instructors to employ the best classroom practices in an effort to optimally engage students in the classroom (Deslauriers et al., 2011), whether from added technology such as electronic response units or clickers (Cramer, Ross, \& Marcoccia, 2010) or active learning exercises. Indeed, high student motivation and engagement in learning have consistently been linked to reduced dropout rates and increased levels of student success (Dev, 1997). Of interest presently are two issues: to what extent does student engagement decrease in the course of a lecture and can that engagement be returned to optimal levels through in-class activities? At this point, we consider two approaches - the traditional model and an alternative - which 
Table 1

Study 1: Telic (Upper Diagonal) and Lecture Engagement (Lower Diagonal) Correlations by Moment, with Moment Means and Standard Deviations $(n=84)$

\begin{tabular}{|c|c|c|c|c|c|c|c|c|}
\hline Moment & 1 & 2 & 3 & 4 & 5 & 6 & $\begin{array}{c}\text { Learning } \\
\text { Engagement } \\
\text { Mean } \\
\end{array}$ & $\begin{array}{c}\text { Learning } \\
\text { Engagement } \\
\text { SD } \\
\end{array}$ \\
\hline 1 & & .66 & .50 & .47 & .37 & .32 & 11.2 & 2.54 \\
\hline 2 & .72 & & .66 & .56 & .45 & .37 & 11.7 & 2.48 \\
\hline 3 & .50 & .57 & & .54 & .54 & .42 & 11.1 & 2.34 \\
\hline 4 & .47 & .42 & .75 & & .79 & .67 & 10.6 & 2.61 \\
\hline 5 & .33 & .23 & .57 & .61 & & .68 & 10.8 & 2.52 \\
\hline 6 & .13 & .15 & .56 & .62 & .64 & & 10.8 & 2.73 \\
\hline Telic Mean & 13.3 & 13.6 & 13.3 & 12.7 & 12.6 & 12.3 & & \\
\hline Telic SD & 2.25 & 2.00 & 2.13 & 2.05 & 2.21 & 2.34 & & \\
\hline
\end{tabular}

Note: Moments represent six times during a lecture when students completed the instrument (10 minutes apart). The upper diagonal contains correlations of telic scores at all combinations of moments. The lower diagonal contains correlations of learning engagement scores. Correlations fall as the moments become more separated.

render opposite predictions and unique directions of advice to classroom instructors.

The traditional approach to student engagement argues that students need firm direction within the lecture and are returned to a goal-directed state by reducing the number of potential distractors: cellular telephones, Internet websites, even neighborly conversations (see McKeachie, 1997). Whereas McKeachie notes the traditional "sage on the stage" method has proven to be largely ineffective, it is undermined by the nature of longer class times (those exceeding $75 \mathrm{~min}$ utes), which necessarily require a brief recess to reinvigorate fatigued students; this may come in the form of active learning exercises spaced 10-15 minutes apart (see Heaslip, Donovan, \& Cullen, 2014; Tangney, 2014). However, an alternative approach (as hypothesized using Reversal Theory) may help to explain how this same outcome can be achieved in situ, throughout an ongoing lecture.

As a metamotivational theory to explain how we transform both emotions and motivations and how we express our personality by the consideration of moment-by-moment experiential states (Lafreniere \& Cramer, 2006; Lafreniere, Menna, \& Cramer, 2013), Reversal Theory (Apter, 1982, 2013) makes a unique prediction concerning one particular pair of motivational states: namely, the telic vs. paratelic states. Reversal Theory posits that people are inclined to change their state from one pole to the other in a motivational pair when (a) they naturally reach satiation, (b) they are frustrated with their current state, or (c) where a change in state is contingent upon an external event or situation (called "contingent reversals", Apter, 2007). Reversal Theory suggests that one defining feature of the telic state is that it reflects serious-mindedness, rather than playfulness. When students experience a switch from a telic to a paratelic state, it is likely they become less focused on attending to lecture content and are more likely to be distracted (or just have fun) so as to satisfy the needs of the paratelic state.

We wished to explore whether it is possible to return students to a telic state by allowing them a paratelic opportunity of experience (for example, by fostering an energetic group activity halfway into the lecture). In a previous laboratory study that examined telic/paratelic reversals in students who freely interacted with statistics tutorial software and video games, one participant reported using the paratelic experience of the video games "to refresh himself" (p. 253) in order to improve his concentration in returning to the telic activity of working through the statistics software (Lafreniere, Cowles, \& Apter, 1988). By this model, giving students an opportunity to switch into the paratelic state - through a lively group activity - should allow them (by satisfaction of their paratelic needs) to subsequently return to a telic or serious-minded state and re-engage with the lecture material. Theoretically then, both telic levels and student engagement with the lecture should rebound.

Note that we are proposing a slightly different idea from the traditional Reversal Theory construct of satiation (Apter, 1982), which refers to the buildup of innate forces over time that bring about a reversal (in the absence of either contingent events or frustration); that is, satiation happens on its own. We are proposing instead a kind of saturation of fulfillment within a state - purposefully allowing full expression of a paratelic state in an attempt to stimulate a reversal; that is, a higher arousal activity in a lecture may help to exhaust or discharge students' paratelic state and return them to a more serious-minded telic state.

Our goals were three-fold: (1) can we track lecture engagement and student telic motivations in the course of an 
ongoing-lecture; (2) can we explain or predict changes in engagement based on telic and paratelic states; (3) and can we improve student engagement during the course of a lecture by manipulating student motivational states through the process of allowing temporary but full expression of their paratelic needs?

\section{Study 1 Method}

\section{Participants and Measures}

We recruited 84 students (73\% female) from an undergraduate social psychology class at a mid-sized Canadian university who participated for partial course credit. At the start of class, students first completed the Paratelic Dominance Scale (Cook \& Gerkovich, 1993), a 12-item measure of the state participants are most likely to experience in the course of a day (internal consistency estimates were high; $\alpha=.83$ despite poor psychometric performance from item9, which we removed). Students then received a questionnaire packet divided into six 7-item units measured using a 5-point scale: four items measured telic levels (as taken from the best performing (internally consistent) items from the Telic/Paratelic State Instrument (O'Connell \& Calhoun, 2001) - feeling playful vs. feeling serious-minded; wanting peace/quiet vs. wanting adventure; trying to accomplish a goal vs. having fun; and wanting to feel more energetic vs. wanting to be less energetic; $(\alpha=.80)$. The other three items measured lecture engagement - the extent to which students were focused on the lecture, interested in the lecture, and engaged in the lecture; $(\alpha=.93)$. At 10-minute intervals throughout the 75-minute lecture, students completed one of the six 7-item units (duration of each was approximately 15 seconds).

\section{Study 1 Results and Discussion}

Significance was set at .05 for all statistical tests. For each of the six moments in the lecture, an overall telic moment score was derived for each student by summing the four constituent items, as was an overall lecture engagement moment score by summing the three constituent items. Table 1 shows the correlations of all combinations of moments for the telic scores in the upper diagonal and for the learning engagement scores in the lower diagonal. Note how the correlations are lower as one moves away from any given moment; that is, correlations are larger when predicting a neighboring moment rather than one several time intervals removed. For example, the correlation between learning engagement scores at intervals 1 and 2 was quite high $(r=.72)$, compared to the correlation between engagement at intervals 1 and $6(r=$ .13).

Table 2 shows the correlations between the telic and learning engagement measures at all combinations of moments. Note that the significant correlations, shown in boldface, tend
Table 2

Study 1: Telic (T) and Lecture Engagement (LE) Correlations with Each Other by Moment $(n=84)$

\begin{tabular}{lllllll}
\hline & T1 & T2 & T3 & T4 & T5 & T6 \\
\hline LE1 & $\mathbf{. 3 2}$ & $\mathbf{. 4 4}$ & .22 & .20 & .07 & .08 \\
LE2 & .21 & $\mathbf{. 4 3}$ & $\mathbf{. 3 6}$ & $\mathbf{. 2 4}$ & .09 & .19 \\
LE3 & .20 & $\mathbf{. 3 8}$ & $\mathbf{. 3 5}$ & .26 & .13 & .15 \\
LE4 & .16 & .14 & .15 &. $\mathbf{2 7}$ & $\mathbf{. 2 3}$ & .17 \\
LE5 & .21 & .18 & .19 & $\mathbf{. 2 3}$ & $\mathbf{. 2 9}$ & .13 \\
LE6 & .06 & .14 & .15 & .15 & .20 & $\mathbf{. 3 0}$ \\
\hline
\end{tabular}

Note: Correlations in boldface are significant at $\mathrm{p}<.05$

to be found along the diagonal, suggesting a moment-bymoment relationship between the telic state and learning engagement. In post-hoc tests, participants' telic dominance scores, as measured by the first instrument used by the students, were not correlated with lecture engagement at all moments $(p>.05)$, but, curiously, were correlated at every oddnumbered moment $(p<.05)$ : Moment $1(r=.344)$, Moment $3(r=.305)$, and Moment $5(r=.234)$; but not Moments 2 , 4 , or $6(p>.05)$.

A repeated-measures factorial analysis of variance was conducted using the six telic moments and the six lecture engagement moments as dependent measures. Results (see Figure 1) showed a significant main effect for telic levels over time, $F(5,76)=4.32, p=.002$; so that participants became progressively less telic (less serious-minded; and more paratelic or playful) as the lecture progressed. Results also showed a significant main effect across time for Lecture Engagement, $F(5,76)=3.06, p=.014$; so that engagement in the lecture dropped significantly as the lecture progressed. There was no significant interaction between telic state and lecture engagement $(p>.05)$, suggesting the two measures dropped at comparable rates.

These results suggest not only that both telic and lecture engagement levels can be successfully tracked during an ongoing lecture, but that the two are correlated - so that lecture engagement descended as students moved into a more paratelic (less serious-minded) state.

Our next research question asks whether students' state can be manipulated so as to return students to a telic (seriousminded) state and enhance student engagement within the lecture. If students retreat from the telic into the paratelic state as a result of distraction and fatigue, then offering a paratelic activity may help to saturate the playful state and motivate students toward a telic serious-minded state, thus enhancing lecture engagement (Apter, 2013). Like Study 1, Study 2 tracked telic and lecture engagement levels, but included a mid-lecture intervention (a paired student activity) to stimulate the paratelic state via saturation. 

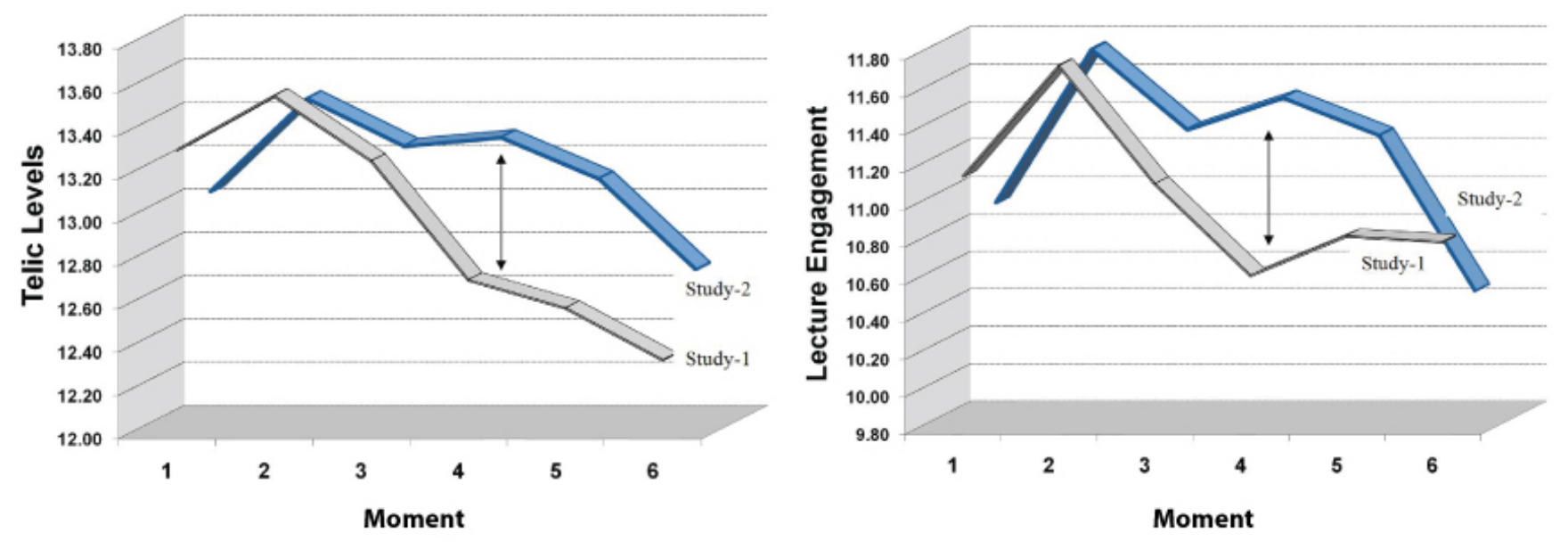

Figure 1. Differences between results of Study 1 and Study 2 in telic state and learning engagement measures over the six moments. The intervention in Study 2 occurred between moments 3 and 4.

\section{Study 2 Method}

\section{Participants, Measures, and Procedure}

In a replication of the first study, we utilized 111 social psychology students (76.7\% female) at the same university who participated for partial course credit. Participants completed the Telic-Paratelic Dominance Scale $(\alpha=.81$; with similar psychometric misbehavior from item 9). Students then received the same 7-item questionnaire packet divided again into 6 units: four items $(\alpha=.80)$ measured telic levels and three items $(\alpha=.95)$ measured lecture engagement. At 10-minute intervals throughout the lecture, students completed each subsequent unit.

The key change between Studies 1 and 2 involved the implementation, between the 3rd and 4th moments in the lecture, with a paratelic activity wherein students worked in pairs to develop creative examples for several of the theoretical concepts discussed in the lecture (for example, everyday examples of social loafing). The goal of this exercise (taking five minutes of lecture time) was to offer an interactive and less serious-minded activity to stimulate a paratelic state via saturation. We observed among students during this recess a lively and light-hearted discussion; thus, we would describe their expressive mood and behavior as playful.

\section{Study 2 Results}

Like Table 1, Table 3 shows the correlations of all combinations of moments for telic scores in the upper diagonal and for learning engagement scores in the lower diagonal, but now for Study 2. Repeated-measures analysis of variance using the six telic moments and the six lecture engagement moments as the dependent variables showed significant changes over time in telic levels, $F(5,105)=2.41, p=.036$.
Similarly, engagement levels dropped over time, $F(5,105)=$ $6.74, p<.001$. The absence of a significant interaction $(p>$ $.05)$ suggests that the telic and engagement levels changed at comparable rates. However, unlike the steadily descending telic and engagement levels observed over time in Study 1, both telic and engagement levels dropped in Study 2 up to (and including) the 3rd moment before they rebounded (immediately following the mid-lecture activity).

A comparison of each telic and engagement moment from Study 1 to Study 2 showed that each of the data points by moment was statistically equivalent, with the exception of Moment 4, where (a) telic levels were marginally lower in Study $1(M=12.71)$ compared to Study $2(M=13.29), t(193)=$ $1.89, p=.06$; and (b) engagement levels were significantly lower in Study $1(M=10.62)$ compared to those in Study 2 $(M=11.48), t(193)=2.58, p=.012$.

\section{General Discussion}

As a follow-up to our first study, the second study showed that (a) we can successfully track telic levels and lecture engagement through the course of a lecture, (b) we can explain changes in lecture engagement due to telic or goal-directed states, and (c) we can enhance lecture engagement by introducing a mid-lecture activity which saturates the paratelic state and induces a reversal to the serious-minded telic state. In short, by introducing a paratelic or playful activity (such as a paired-up or large group exercise) mid-way through an ongoing lecture, students can express a more paratelic state, saturate it, and feel motivated to entertain a more seriousminded telic state. The implication here is that instructors should be encouraged to utilize interactive class activities in an effort to maintain high levels of engagement because stu- 
Table 3

Study 2: Telic (Upper Diagonal) and Lecture Engagement (Lower Diagonal) Correlations by Moment, with Moment Means and Standard Deviations $(n=111)$

\begin{tabular}{lcccccccc}
\hline Moment & 1 & 2 & 3 & 4 & 5 & 6 & $\begin{array}{c}\text { Learning } \\
\text { Engagement } \\
\text { Mean }\end{array}$ & $\begin{array}{c}\text { Learning } \\
\text { Engagement } \\
\text { SD }\end{array}$ \\
\hline 1 & & .71 & .52 & .33 & .44 & .39 & 10.9 & 2.95 \\
2 & .66 & & .64 & .42 & .41 & .38 & 11.7 & 2.86 \\
3 & .57 & .77 & & .44 & .41 & .45 & 11.3 & 3.1 \\
4 & .55 & .67 & .75 & & .58 & .48 & 11.5 & 2.97 \\
5 & .47 & .57 & .63 & .74 & & .64 & 11.3 & 3.09 \\
6 & .46 & .48 & .57 & .68 & .77 & & 10.8 & 2.73 \\
\hline Telic Mean & 13 & 13.5 & 13.3 & 13.3 & 13.1 & 12.7 & & \\
Telic SD & 2.89 & 2.51 & 2.39 & 2.17 & 2.11 & 2.37 & & \\
\hline
\end{tabular}

Note: Moments represent six times during a lecture when students completed the instrument (10 minutes apart). The upper diagonal contains correlations of telic scores at all combinations of moments. The lower diagonal contains correlations of learning engagement scores. In this study a paratelic intervention (a paired student activity) occurred between moments 3 and 4 .

dents use these activities to satisfy their paratelic needs and re-engage with the course material.

Critics may charge that without a direct measure of students' state during the mid-lecture activity, it is impossible to say whether the task was in fact paratelic in nature. This point carries some merit, since it was arguably never assessed in the course of the mid-lecture activity. From its phenomenological basis, Reversal Theory does not posit to be certain that an individual is in any given state - rather it implies this based on observed mood and behaviour. As such, we did observe behaviour and mood during the activity that could be regarded as light-hearted, enjoyable, playful, and lively. As such, we are confident the students found the mid-lecture activity to be paratelic in nature.

Critics may further argue that since the two studies were conducted on different participating students at different times, an artifact of time may have played a role. However, we urge readers to see that moments hypothesized not to be different between the two studies (i.e., those without paratelic saturation, namely all moments but the 4th) were not different, and those moments hypothesized to be different between the two studies (namely the 4th moment) were different.

We encourage researchers and practitioners to further explore the notion of saturation as an interventional technique. Of interest for future research is the question of how many paratelic activities should be introduced in the course of a lecture (as per the time specified) so as to maximally optimize student engagement (Heaslip, Donovan, \& Cullen, 2014). Several different types of mid-lecture activities can be compared for their relative efficacy in engagement, for example relaxation, taking a minute to review notes or the textbook, or noting a question one might wish to ask (Tangney, 2014). Additional questions may address the interaction be- tween personality and telic levels during lecture engagement (Lafreniere \& Cramer, 2006; Lafreniere et al., 2013). Finally, whereas the present studies examined levels of student engagement, follow-up assessments could be introduced to determine if student learning is enhanced by the introduction of paratelic activities mid-lecture.

\section{References}

Ahlfeld, S., Mehta, S., \& Sellnow, T. (2005). Measurement and analysis of student engagement in university classes where varying levels of PBL methods of instruction are in use. Higher Education Research and Development, 24, 5-20.

Apter, M. J. (1982). The experience of motivation: A theory of psychological reversals. London and New York: Academic Press.

Apter, M. J. (2013). Developing Reversal theory: Some suggestions for future research. Journal of Motivation, Emotion, and Personality, 1, 1-8.

Axelson, R. D., \& Flick, A. (2010). Defining student engagement. Change: The Magazine of Higher Learning, 43, 38-43.

Baron, P., \& Corbin, L. (2012). Student engagement: Rhetoric and reality. Higher Education Research and Development, 31, 759-772.

Coates, H. (2005). The value of student engagement for higher education quality assurance. Quality in Higher Education, 11, 25-36.

Cook, M. R., \& Gerkovich, M. M. (1993). The development of a Paratelic Dominance Scale. Advances in Reversal theory. $177-188$. 
Cramer, K. M. (2013). Six criteria of a viable theory: Putting Reversal theory to the test. Journal of Motivation, Emotion, and Personality, 1, 9-16.

Cramer, K. M., Ross, C., \& Marcoccia, A. (2010). Efficacy of electronic voting: Addressing the value of clickers with new research controls. Academic Exchange Quarterly, 14, 30-34.

Deslauriers, L., Schelew, E., \& Wieman, C. (2011). Improved learning in a large enrollment physics class. Science, 332, 862-864.

Dev, P. C. (1997). Intrinsic motivation and academic achievement: What does their relationship imply for the classroom teacher? Remedial and Special Education, 18, 1219.

Heaslip, G., Donovan, P., \& Cullen, J. G. (2014). Student response systems and learner engagement in large classes. Active Learning in Higher Education, 15, 11-24.

Kahu, E. R. (2013). Framing student engagement in higher education. Studies in Higher Education, 38, 758-773.

Krause, K., \& Coates, H. (2008). Students' engagement in first-year university. Assessment and Evaluation in Higher Education, 33, 493-505.

Kuh, G. D. (2001). Assessing What Really Matters to Student Learning Inside The National Survey of Student Engagement. Change: The Magazine of Higher Learning, 33, 10-17.

Kuh, G. D. (2003). What We're Learning About Student Engagement From NSSE: Benchmarks for Effective Educational Practices. Change: The Magazine of Higher Learning, 35, 24-32.

Lafreniere, K. D., Cowles, M. P., \& Apter, M. J. (1988). The reversal phenomenon: Reflections on a laboratory study.
In M. J Apter, J. H. Kerr, \& M. P. Cowles (Eds.), Progress in reversal theory (pp. 247-254). Amsterdam: NorthHolland.

Lafreniere, K. D., \& Cramer, K. M. (2006). Examining reversal theory measures in relation to NEO personality dimensions and consideration of future consequences. Personality and Individual Differences, 40, 1387-1397.

Lutze-Mann, L., \& Kumar, R. K. (2013). The formative assessment lecture: Enhancing student engagement. Medical Education, 45, 526-527.

McCormick, A. C., Kinzie, J., \& Gonyea, R. M. (2013). Student engagement: Bridging research and practice to improve the quality of undergraduate education. Higher Education: Handbook of Theory and Research, 28, 47-92.

Mundy, D. P., \& Consoli, R. (2013). Here be dragons: Experiments with the concept of 'Choose Your Own Adventure' in the lecture room. Innovations in Education and Teaching International, 50, 214-223.

O'Connell, K. A., \& Calhoun, J. E. (2001). The Telic/Paratelic State Instrument (T/PSI): Validating a reversal theory measure. Personality and Individual Differences, 30, 193-204.

Tangney, S. (2014). Student-centred learning: A humanist perspective. Teaching in Higher Education, 19, 266-275.

Winstone, N., \& Millward, L. (2012). Reframing perceptions of the lecture from challenges to opportunities: Embedding active learning and formative assessment into the teaching of large classes. Psychology Teaching Review, 18, 31-41. 